\title{
To study the correlation of serum lactate dehydrogenase (LDH) levels in women with preeclampsia on maternal and perinatal outcome
}

\author{
K. Omkara Murthy ${ }^{1}$, B. S. Dhananjaya ${ }^{2}$, S. Shazi ${ }^{3}$ \\ ${ }^{1}$ Dr. Omkara Murthy K., Professor, ${ }^{2}$ Dr. Dhananjaya B. S., Professor and Head, ${ }^{3}$ Dr. Shazi Siddiqui, Post Graduate, all \\ authors are affiliated with Department of Obstetrics and Gynecology, Sri Siddhartha Medical College Hospital and \\ Research Center, Tumakuru, Karnataka, India.
}

Corresponding Author: Dr. Shazi Siddiqui, Department of Obstetrics and Gynaeclogy, Sri Siddhartha Medical College Hospital and Research Centre, Tumakuru, Karnataka, India. E-mail: drshazisiddiqui@gmail.com

\begin{abstract}
Introduction: Pre-eclampsia is a multi-system disorder of unknown etiology and a major cause of maternal and perinatal complications. LDH is an intracellular enzyme and is increased when there is increased cell death. As pre-eclampsia leads to cellular death, so LDH levels can beused to assess the severity of disease. Aim: To study the correlation of levels of serum LDH in women with preeclampsia on maternal and perinatal outcome. Objectives: To correlate the maternal and perinatal outcomes with serum LDH levels. To assess serum LDH as a marker for severity of preeclampsia. Materials and Methods: A prospective comparative studywas conducted over a period of 18 months from November 2016 to April 2018 in the department of Obstetrics and Gynecology, Sri Siddhartha Medical Hospital, Tumakuru. Out of 180 women studied, 100 were normal pregnant women, 40 patients were having mild preeclampsia and 40 patients were having severe preeclampsia. The two groups and subgroups were studied based on age, gravidity, trimester, investigations, maternal and perinatal outcome, complications and follow up. Results: Higher values of LDH were found in mild and severe preeclamptic women than those of normal pregnant women in third trimester and was statistically significant. Severe lypreec lamptic patients had increased LDH levels which in association with investigations, outcome, complications and follow up was significant. Conclusion: LDH is a useful biochemical marker and can be considered as a supportive prognostic tool thatreflects the severity and complications of preeclampsia. Identification of high-risk patients, their close monitoring, and correct management may prevent these complications.
\end{abstract}

Keywords: Preeclampsia, Serum Lactate Dehydrogenase (LDH), Hypertensive disorders of pregnancy

\section{Introduction}

Hypertensive disorders complicate 5 to 10 percent of all pregnancies, although incidence varies among different hospitals, regions, and countries [1]. These disorders are a major cause of maternal and perinatal mortality and morbidity worldwide [2]. Preeclampsia is still regarded as disease of theories and its etiology has been poorly understood.

The analysis of biochemical markers particularly markers related to vascular dysfunction such as LDH, AST, uric acid may enrich the ability to predict and prevent preeclampsia in near future [3]. Lactate dehydrogenase (LDH) is an intracellular enzyme which converts pyruvic acid to lactic acid during glycolysis.

Manuscript received: $18^{\text {th }}$ January 2019

Reviewed: $28^{\text {th }}$ January 2019

Author Corrected: $2^{\text {nd }}$ February 2019

Accepted for Publication: $6^{\text {th }}$ February 2019
LDH gene expression and activity are higher in placentas of preeclampsia than normal pregnancy. LDH has five is forms and among this LDHA4 seen in preeclampsia is most responsive to hypoxia. Elevated levels of LDH indicates cell damage and dysfunction.

The multiorgan dysfunction in preeclampsia caused by vascular end othelial damage leads to excessive LDH leakage and elevated levels in serum due to cellular dysfunction, which may cause the occurrence of preeclampsia [4].

So it can be used as a biochemical marker as it reflects the severity of the disease, occurrence of complications and fetal outcome [5]. The present study has been undertaken to study the correlation of serum lactate dehydrogenase (LDH) levels in women with preeclampsia on maternal and perinatal outcome. 


\section{Materials and Methods}

Setting: The study was conducted over a period of 18 months from November 2016 to April 2018 in the Obstetrics and Gynaecology department, Sri Siddhartha Medical College and Hospital, Tumakuru on 180 antenatal cases attending the OPD or admitted as inpatients.

Type of Study: Prospective comparative study Sampling method: Consecutive sampling

Sample Collection: All ANC women who had come in the study period were taken up for the study. Blood pressure was measured and proteinuria was checked in these women and they were grouped as-

Group 1- Healthy normotensive pregnant women (Controls), Group 2- Patients of preeclampsia and eclampsia (Subjects).

Subjects were recruited into following subgroups: Sub group A- Mild Preeclampsia and Sub group B- Severe Preeclampsia Subjects would also be divided according to the serum LDH levels into following groups.

(a) < $600 \mathrm{IU} / 1$ (b) 600-800 IU/1(c) > $800 \mathrm{IU} / 1$

The two groups and subgroups were studied based on age, gravidity, trimester, investigations, maternal and perinatal outcome, complications and follow up. All women were followed until delivery and post partum period and babies till neonatal period.

Measurement of blood pressure: Blood pressure of the patients was measured on right upper limb in the semi recumbent position with the arm at the heart level with a mercury sphygmomanometer. Two-third arm was covered and the arm cuff was above cubital crease (half inch) and the tubes were above brachial artery. Blood pressure was measured by sphygmomanometer. Systolic blood pressure was recognized by the appearance of tapping sounds (Korotkoff I). Korotkoff
$\mathrm{V}$ (disappearance of the sound) was used to determine diastolic blood pressure.

Estimation of serum Lactate Dehydrogenase: Plain blood sample was collectedfor analysis of LDH which was done in fully automated biochemistry analyzer.

Serum LDH levels were done in the biochemistry laboratory. The method is based on the reduction of pyruvate to lactate in the presence of $\mathrm{NADH}$ by the action of lactate dehydrogenase. The pyruvate that remains unchanged with 2, 4-Dinitrophenylhydrazone, which is determined calorimetrically in an alkaline medium.

Inclusion criteria: All singleton pregnancies $\geq 28$ weeks of gestation were enrolled in this study

Exclusion criteria: Preexisting diabetes mellitus, Essential Hypertension, Renal disease, Liver disorder, Hypothyroidism, Hyperthyroidism, Convulsions due to any other cause, Urinary tract infection

Statistical Analysis: After data collection, data entry was done in Excel worksheet. Data analysis was done with help of SPSS 18.0, and R environment ver.3.2.2. Quantitative data was presented with the help of Mean, Standard deviation, Median, Interquartile range. Analysis of variance (ANOVA) has been used to find the significance of study parameters between three or more groups of patients. Chi-square/Fisher Exact test has been used to find the significance of study parameters on categorical scale between two or more groups, non-parametric setting for Qualitative data analysis. Fisher Exact test used when cell samples are very small.

Ethical clearance: was obtained from the institution and informed consent was taken from patients.

\section{Results}

Table-1: Demographic data of the three groups.

\begin{tabular}{|c|c|c|c|}
\hline Variables & Normotensive N=100 & Mild Preeclampsia N=40 & Severe Preeclampsia N=40 \\
\hline Age* $^{*}$ & $22.79 \pm 2.48$ & $24.80 \pm 3.35$ & $24.08 \pm 2.66$ \\
\hline Education Level Illiterate & $60(60 \%)$ & $26(65 \%)$ & $23(57.5 \%)$ \\
\hline Literate & $40(40 \%)$ & $14(35 \%)$ & $17(42.5 \%)$ \\
\hline Antenatal Visits Booked & $60(60 \%)$ & $19(47.5 \%)$ & $18(45 \%)$ \\
\cline { 2 - 4 } & $40(40 \%)$ & $21(52.5 \%)$ & $22(55 \%)$ \\
\hline Unbooked & $2.6 \pm 0.5$ & $1.8 \pm 0.9$ & $1.3 \pm 0.4$ \\
\hline Parity* & $38.45 \pm 2.87$ & $36.54 \pm 1.54$ & $34.58 \pm 2.6$ \\
\hline POG** & & & \\
\hline
\end{tabular}


POG- Period of Gestation

Values Are Given As Mean \pm Sd

*P Value: $0.05<\mathrm{P}<0.10$ (moderately significant)

**P Value: $\mathrm{P} \leq 0.01$ (strongly significant)

As seen in Table 1, in the present study majority of patients in the study group were illiterates in all the three groups. Majority of normotensive pregnant women were booked cases and majority of preeclamptic pregnant women were unbooked cases. But observed difference was not statistically significant. $71 \%$ of the patients in normotensive group were primigravida, while $62.5 \%$ in mild preeclampsia group were primigravida and $72.5 \%$ in severe preeclampsia group were primigravida but difference was moderately significant. Most common age group was 20-30 years. The three groups were compared with respect to trimester. All the cases belonged to the third trimester. In the study majority of the patients in the normal pregnancy group delivered after 37 completed gestational weeks, whereas in the severe preeclamptic group, patients delivered before 34 gestational weeks. The difference was statistically significant.

Table-2: Hemodynamics and Laboratory Data of The Three Groups.

\begin{tabular}{|c|c|c|c|}
\hline Variables & $\begin{array}{c}\text { Normotensive } \\
\mathbf{N}=\mathbf{1 0 0}\end{array}$ & $\begin{array}{c}\text { Mild preeclampsia } \\
\mathbf{N = 4 0}\end{array}$ & $\begin{array}{c}\text { Severe preeclampsia } \\
\mathbf{N}=\mathbf{4 0}\end{array}$ \\
\hline Systolic BP $(\mathrm{mmHg})^{* *}$ & $120.12 \pm 9.47$ & $148.30 \pm 6.54$ & $172.55 \pm 9.65$ \\
\hline Diastolic BP $(\mathrm{mmHg})^{* *}$ & $77.94 \pm 9.27$ & $98.35 \pm 4.25$ & $116.35 \pm 5.39$ \\
\hline LDH** $^{* *}$ & $286.75 \pm 100.68$ & $555.85 \pm 133.44$ & $711.88 \pm 119.05$ \\
\hline Urine albumin $(\mathrm{mg})^{*}$ & $0.2 \pm 0.1$ & $0.3 \pm 0.2$ & $1.0 \pm 0.4$ \\
\hline PT $^{*}$ & $11.49 \pm 0.72$ & $12.47 \pm 1.00$ & $18.00 \pm 2.44$ \\
\hline aPTT & $26.68 \pm 3.34$ & $27.80 \pm 4.34$ & $0.98 \pm 0.15$ \\
\hline INR* & $0.89 \pm 0.08$ & $0.94 \pm 0.13$ & $7.42 \pm 2.20$ \\
\hline Haemoglobin** & $10.18 \pm 1.33$ & $8.48 \pm 1.51$ & $96.5 \pm 89$ \\
\hline Platelet count $\left(\times 10^{9}\right)^{*}$ & 204.34 .7 & $108 \pm 32.8$ & $31.79 \pm 4.55$ \\
\hline Blood urea & $27.20 \pm 3.92$ & $27.53 \pm 4.06$ & $0.95 \pm 0.17$ \\
\hline Serum creatinine & $0.84 \pm 0.012$ & $3.73 \pm 0.37$ & $5.87 \pm 0.36$ \\
\hline Serum uric acid* & $2.58 \pm 0.41$ & $3.73 \pm 0.37$ & \\
\hline
\end{tabular}

LDH - Lactate Dehydrogenase, PT- Prothrombin Time, aPTT - Partial Prothrombin Time

Table 2 shows that the mean SBP in normotensive, mild preeclampsia and severe preeclampsia group were $120.12 \pm 9.47$, $148.30 \pm 6.54$ and $172.55 \pm 9.65$ respectively. The difference was statistically significant. The mean DBP in normotensive, mild preeclampsia and severe preeclampsia group were $77.94 \pm 9.27,98.35 \pm 4.25$ and $116.35 \pm 5.39$ respectively. The difference was statistically significant. The mean LDH levels were $286.75 \pm 100.68,555.85 \pm 133.44$ and $711.88 \pm 119.05$ respectively in each group and it was statistically significant. The difference in haemoglobin levels were statistically significant. Urine albumin, prothrombin time, INR, platelet count and serum uric acid levels were moderately significant.

Table-3: Pregnancy Outcome \& Level of LDH

\begin{tabular}{|c|c|c|c|}
\hline Variables & $\begin{array}{c}\text { LDH }<\mathbf{6 0 0} \text { IU/1 } \\
\mathbf{N}=\mathbf{5}\end{array}$ & $\begin{array}{c}\text { LDH 600-800 IU/1 } \\
\mathbf{N}=\mathbf{2 4}\end{array}$ & $\begin{array}{c}\text { LDH }>\mathbf{8 0 0} \text { IU/1 } \\
\text { N=11 }\end{array}$ \\
\hline Mode Of Delivery NVD & $2(15.4 \%)$ & $11(84.6 \%)$ & $0(0 \%)$ \\
\hline Cesarean Section** & $3(11.1 \%)$ & $13(48.1 \%)$ & $11(40.8 \%)$ \\
\hline Birth Weight LBW* & $1(4.5 \%)$ & $11(50 \%)$ & $10(45.5 \%)$ \\
\hline Normal & $4(22.2 \%)$ & $13(72.2 \%)$ & $1(5.6 \%)$ \\
\hline
\end{tabular}

NVD -Normal Vaginal Delivery, LBW - Low Birth Weight 


\section{Original Research Article}

Majority of the patients underwent normal vaginal delivery but maximum number of patients in severe preeclamptic group underwent lower segment caesarean section in which majority had LDH levels $>800 \mathrm{IU} / 1.45 .5 \%$ of the low birth weight babies were seen in LDH levels >800IU/1, 50\% were seen in between 600-800 IU/1 and with serum LDH levels $<600 \mathrm{IU} / 1$ only $4.5 \%$ of babies were seen. Both were statistically significant as shown in Table 3 .

Table-4: Complications of Severe Pre-Eclampsia According \& LDH level.

\begin{tabular}{|c|c|c|c|}
\hline Complications & $\begin{array}{c}\mathrm{LDH}<600 \mathrm{IU} / \mathbf{l} \\
\mathrm{N}=5\end{array}$ & $\begin{array}{c}\text { LDH 600-800IU/1 } \\
\qquad \begin{array}{c}\mathrm{N}=\mathbf{2 4}\end{array}\end{array}$ & $\begin{array}{c}\mathrm{LDH}>\mathbf{8 0 0 I U} / \mathbf{1} \\
\mathrm{N}=11\end{array}$ \\
\hline Abruptio Placentae * & $0(0 \%)$ & $0(0 \%)$ & $2(18.2 \%)$ \\
\hline Post Partum Haemorrhage & $0(0 \%)$ & $0(0 \%)$ & $3(27.2 \%)$ \\
\hline Renal Failure & $0(0 \%)$ & $0(0 \%)$ & $0(0 \%)$ \\
\hline IPE/PPE* & $0(0 \%)$ & $0(0 \%)$ & $2(18.2 \%)$ \\
\hline HELLP* & $0(0 \%)$ & $0(0 \%)$ & $2(18.2 \%)$ \\
\hline Cerebral Haemorrhage & $0(0 \%)$ & $0(0 \%)$ & $0(0 \%)$ \\
\hline Pulmonary Edema & $0(0 \%)$ & $0(0 \%)$ & $0(0 \%)$ \\
\hline No Other Complications & $5(100 \%)$ & $24(100 \%)$ & $2(18.2 \%)$ \\
\hline
\end{tabular}

IPE- Intrapartum Eclampsia, PPE- Postpartum Eclampsia, HELLP- Hemolysis, Elevated Liver Enzymes, Low Platelets

Maternal complications like abruptio placentae, post partumhaemorrhage, intra partum eclampsia, post partum eclampsia and HELLP syndrome were seen in severe pre eclamptic group with serum LDH levels >800IU/1.(Table 4)

Table-5: Neonatal Outcome According Tothe Level of LDH

\begin{tabular}{|c|c|c|c|}
\hline NeonatalOutcome & $\begin{array}{c}\text { LDH }<\mathbf{6 0 0} \text { IU/1 } \\
\mathbf{N}=\mathbf{5}\end{array}$ & $\begin{array}{c}\text { LDH 600-800 IU/1 } \\
\mathbf{N}=\mathbf{2 4}\end{array}$ & $\begin{array}{c}\text { LDH }>\mathbf{8 0 0} \text { IU/1 } \\
\text { N=11 }\end{array}$ \\
\hline IUGR** & $3(20 \%)$ & $10(66.7 \%)$ & $2(13.3 \%)$ \\
\hline Birth Asphyxia** & $0(0 \%)$ & $0(0 \%)$ & $3(100 \%)$ \\
\hline Still Birth* & $0(0 \%)$ & $0(0 \%)$ & $3(100 \%)$ \\
\hline NICU** & 2() $14.3 \%$ & $11(78.6 \%)$ & $1(7.1 \%)$ \\
\hline Neonatal Death & $0(0 \%)$ & $0(0 \%)$ & $2(100 \%)$ \\
\hline No Other Complications & $0(0 \%)$ & $3(100 \%)$ & $0(0 \%)$ \\
\hline
\end{tabular}

IUGR- Intra Uterine Growth Retardation

Table-6: Association of follow up of neonates between 3 groups.

\begin{tabular}{|c|c|c|c|}
\hline Variables & $\begin{array}{c}\text { Normotensive } \\
\mathbf{N}=\mathbf{1 0 0}\end{array}$ & $\begin{array}{c}\text { Mild Preeclampsia } \\
\mathbf{N = 4 0}\end{array}$ & $\begin{array}{c}\text { Severe Preeclampsia } \\
\mathbf{N}=\mathbf{4 0}\end{array}$ \\
\hline Neonatal Pathological Jaundice & $0(0 \%)$ & $3(7.5 \%)$ & $7(17.5 \%)$ \\
\hline Neonatal Sepsis & $0(0 \%)$ & $0(0 \%)$ & $6(15 \%)$ \\
\hline
\end{tabular}

Neonatal complications like intra uterine growth retardation, birth asphyxia, still birth and NICU admission were seen in neonates who were born to preeclamptic mothers and majority of the neonatal complications were seen in serum LDH levels $>800 \mathrm{IU} / 1$. Neonatal pathological jaundice was seen in neonates who were born to preeclamptic women with serum LDH levels $>600 \mathrm{IU} / 1$. Majority of the neonatal sepsis were seen in those neonates who were born to severe preeclamptic women and had serum LDH levels $>800 \mathrm{IU} / 1$. (Table 5 and 6). 


\section{Original Research Article}

\section{Discussion}

In the present study majority of patients $(60.6 \%)$ in the study group were illiterates in all the three groups. Andrews L colleagues (2014) did a similar study and concluded that $56.7 \%$ of the patients were illiterate [6]. This shows that literacy plays a vital role in preventing pregnancy related complications.

Majority of normotensive pregnant women were booked cases and majority of preeclamptic pregnant women were unbooked cases. But observed difference was not statistically significant ( $\mathrm{P}$ 0.180). In a similar study done by Behara NR and coworkers majority (62\%) of the patients had no antenatal care [7]. This showed that the patients who took regular antenatal checkups had less chances of having preeclampsia and associated complications.

In the present study, age of most pregnancies occurred in the age group of 20-30 years and mean age was $23.52 \pm 2.85$ in all the three groups and which was similar to the studies done earlier by Talwar P et aland Mary VP et alwhere majority of the patients belonged to younger age group $[8,9]$.

In present study $72.5 \%$ of the patients in severe preeclampsia group were primigravida, while in mild preeclampsia $62.5 \%$ were primigravida and $71 \%$ in normotensive group which was moderately significant. The findings were similar to the studies done earlier by Jain R et al, Gopinath $\mathrm{S}$ et al and Umasatyasri $\mathrm{Y}$ et al which showed majority of the patients were primigravida in preeclamptic women. Thus the probability of having preeclampsia during pregnancy is higher in primigravida $[10,11,12]$.

When there was severe preeclampsia, we rarely continued the pregnancy beyond 34 weeks and plan of action was to deliver immediately, prevent seizure and control blood pressure. In mild preeclamptic patients the pregnancy was continued upto 37 weeks but if any untoward complications were faced, pregnancy was terminated. It was observed that higher the LDH level, earlier the termination while patients with lower and normal LDH levels pregnancy was continued.

In the present study, control group (normotensive group) all had levels of $<600 \mathrm{IU} / 1$, the mean value of LDH being $286.75 \pm 100.68 \mathrm{IU} / 1$. Most of the patients in mild preeclampsia group had levels <600 IU/1. 16 patients $(40 \%)$ had $\mathrm{LDH}$ in the range of $600-800 \mathrm{IU} / 1$. The mean LDH level calculated as 555.85 $\pm 133.44 \mathrm{IU} / 1$.
Out of 40 cases of severe preeclampsia, 5 cases (12.4\%) had LDH levels <600 IU/1, 24 cases (60\%) had LDH levels between 600 and $800 \mathrm{IU} / 1$ and 11 cases (27.5\%) had LDH levels above $800 \mathrm{IU} / 1$. It was found that majority of preeclamptic women had abnormal levels of LDH and was significantly increased among mildand severe preeclamptic women when compared with normotensive controls. Highly significant increase in $\mathrm{LDH}$ level was found in women with severe preeclampsia as compared with mild preeclampsia.

On analyzing the above data it is clearly observed that there is significant rise in the LDH levels with increasing severity of the disease $(\mathrm{P}<0.001)$ which was seen in studies done by Rajoria L et al, Dev SV et al and Bhave NV et al[13,14,15].

Majority of the patients $(81.8 \%)$ had anemia with serum LDH levels $>800 \mathrm{IU} / \mathrm{l}$. One of the known complication of anaemia is preeclampsia which seen in our study.

Greater the severity of anemia higher is the severity of preeclampsia. In a study done by Gupta G (2018) it was concluded that the risk of perinatal and maternal morbidity increases with the severity of anaemia when associated with preeclampsia [16].

In the present study thrombocytopenia was found in severe preeclampsia which is a predictor of HELLP syndrome. Greater the severity of preeclampsia, lower will be the platelet count. Similar to this finding was seen in others studies done by Kant RH et albut study done by Qublan HS et al it was not statistically significant. Severe grade of proteinuria is associated with elevated LDH levels $[17,18]$.

In severe preeclampsia group LSCS was done in $67.5 \%$ of patients while $37.5 \%$ in mild pre eclampsia had undergone LSCS and only $21 \%$ of normotensive patients had undergone LSCS. The difference was found to be statistically significant $(\mathrm{P}<0.001)$.

This discrepancy in caesarean may be explained by the high percentage of intra uterine growth restriction and fetal distress. In accordance to the present study was by Singh $\mathrm{P}$ where the percentage of women delivering by LSCS increased as the levels of LDH increased in preeclamptic group [19]. Majority of the babies born to the patients with severe preeclampsia had significantly lower birth weight when compared to normotensive patients and was statistically significant. 


\section{Original Research Article}

Maternal complications like abruptio placentae, post partumhaemorrhage, intra partum eclampsia, post partum eclampsia and HELLP syndrome were seen in severe preeclamptic group in the study and it was observed that these patients had serum LDH levels $>800 \mathrm{IU} / 1$. Catanzerite et al. reported a subgroup of patients who had elevated levels of LDH manifested with hemolysis, elevated liver enzymes, low platelet count (HELLP) syndrome and were at a high risk for developing maternal mortality [20].

Neonatal complications like intra uterine growth retardation, birth asphyxia, still birth and NICU admission were seen in neonates who were born to preeclamptic mothers and majority of the neonatal complications were seen in serum LDH levels $>800 \mathrm{IU} / 1$. Ciryam SS also found association between poor obstetric outcome (low birth weight, IUGR, perinatal death and preterm births) and increasing levels of serum LDH. Malerewicz et al, concluded that acute clinical symptoms that endanger fetal life in preeclampsia correlate well with distinct activity of LDH $[21,22]$.

After following up of mothers upto six all were found to be healthy. Neonates were followed upto one month and in that 2 neonatal death (cause of the death for one neonate was prematurity and for another one was low birth weight) was noted who were born to severe preeclamptic women and had serum LDH levels $>800$ IU/1. Neonatal pathological jaundice (NPJ) was seen in neonates who were born to preeclamptic women and all of the neonates mothers who had NPJin severe preeclamptic group had serum LDH levels $>800$ IU/1.

Majority of the neonatal sepsis were seen in those neonates who were born to severe preeclamptic women and had serum LDH levels $>800 \mathrm{IU} / 1$.

\section{Conclusion}

Preeclampsia is one of the important causes for maternal mortality in India as well as other developing countries. Hence there is a search for predictors and prognostic markers. Raised LDH is associated with preeclampsia and higher the LDH levels more are the chances of complications. Hence serum LDH can be measured in all pregnant women to predict preeclampsia. Proper monitoring of serum LDH levels in a high risk pregnant woman may help in early diagnosis and early intervention. As it predicts the severity of the disease it can be used as a reliable biochemical marker to identify high risk patients for close monitoring, prompt and correct management and hence help in preventing complications, decreasing maternal, foetal and neonatal morbidity and mortality.

What this study adds to existing knowledge: Preeclampsia is a condition which has no etiology. Morbidity and mortality can be reduced if preeclampsia can be diagnosed at a stage where it can be prevented totally or at least we can take secondary preventive measures.

Hence there is a search for predictors and prognostic markers. Raised LDH is associated with preeclampsia and higher the LDH levels more are the chances of complications. Not many studies are available regarding this hence it can be used as a predictor.

Authors Contributions: Conceptualization, study design, writing the paper: K. Omkara Murthy. Analysis: B S Dhananjaya. Carried out study, collection of data, writing the paper: S Shazi.

\section{Funding: Nil, Conflict of interest: Nil Permission from IRB: Yes}

\section{References}

1. Cunningham FG, Leveno KJ, Bloom SL, Spong CY, Dashe JS, Hoffman BL, Casey BM, Sheffield JS. William Obstetrics. 24 ${ }^{\text {rd }}$ ed. New York. Mc Graw-Hill Education; 2014: 728-79.

2. Gabbe SG, Niebyl JR, Simpson JL, Landon MB, Galan HL, Jauniaux ERM, Driscoll DA, Berghella V, Grobman WA. Obstetrics Normal and Problem Pregnancies. $7^{\text {th }}$ ed. China. Elsevier; 2017: 662-703.

3. Hak J, Un-Nisa N, Gupta S. LDH Levels in Pregnancy and its Association with Severity of the Disease and Feto-maternal Outcome in Pre-eclampsia and Eclampsia. Jk science. 2015; 17(3): 110-13.

4. Sarkar PD, Sogani S. Evaluation of serum lactate dehydrogenase and gamma glutamyl transferase in preeclamptic pregnancy and its comparison with normal pregnancy in third trimester. Int J Res Med Sci. 2013; 1 (4): 365-68.

5. Thamilkothai R, Bhavanidevi V, Ramalakhsmi S. Role of Serum Lactate Dehydrogenase As A Prognostic Biochemical Marker in Pre-Eclampsia And Eclampsia. Ind J Res. 2016; 5(5): 187-88.

6. Andrews L et al. Maternal outcome in relation to Biochemical parameters in Hypertensive disorders in Pregnancy. IOSR-JDMS. 2014; 13(2): 18-22. 


\section{Original Research Article}

7. Behera NR, Patel J. Maternal outcome in antepartum eclampsia caesarean versus vaginal delivery. Int $\mathbf{J}$ Reprod Contracept Obstet Gynecol. 2018; 7 (4): 1330-35.

8. Talwar P, Kondareddy T, Pranidha CA. LDH as a prognostic marker in hypertensive pregnancy. Int $\mathrm{J}$ Reprod Contracept Obstet Gynecol. 2017; 6 (6): 2444-46.

9. Mary VP, Chellatamizh M, Padmanaban S. Role of serum LDH in preeclampsia as a prognostic factor - a cross sectional case control study in tertiary care hospital. Int J Reprod Contracept Obstet Gynecol. 2017; 6 (2): 595-98.

10. Jain R, Upadhyay C, Mehta L, Nayak B, Desai G. Lactic dehydrogenase as a biochemical marker of adverse pregnancy outcome in severe pre-eclampsia, Gujarat. Int J ReprodContracept Obstet Gynecol. 2017; $6(8): 3418-22$.

11. Gopinath S, Shafi M, Ramegowda HK, Mehta PK. Outcome of referred obstetric emergencies at a tertiary centre. Int J Biol Med Res. 2016; 7(2): 5518-21.

12. Umasatyasri Y, Vani I, Shamita P. Role of LDH (Lactate dehydrogenase) in preeclampsia-eclampsia as a prognostic marker: An observational study. IAIM. 2015; 2(9): 88-93.

13. Rajoria L, Nenkar S, Gidwani C. Lactic acid dehydrogenase and uric acid as prognostic markers for hypertensive disorders of pregnancy. IJSAR. 2018; 5 (2): 12-17.

14. Dave A, Maru L, Jain A. LDH (Lactate Dehydrogenase) : A Biochemical Marker for the Prediction of Adverse Outcomes in Pre-eclampsia and Eclampsia. J ObstetGynaecol India. 2016 Feb; 66 (1):23-9. doi: 10.1007/s 13224-014-0645-x. Epub 2014

Dec 2.
15. Bhave NV, Shah PK. A correlation of lactate dehydrogenase enzyme levels in pregnancy induced hypertensive disorders with severity of disease, maternal and perinatal outcome. Int $\mathrm{J}$ Reprod Contracept Obstet Gynecol. 2017; 6(10): 4302-08.

16. Gupta G. A case control study to evaluate correlation of anaemia with severe preeclampsia. Int $\mathrm{J}$ Reprod Contracept Obstet Gynecol. 2018;7(7):2773-77.

17. Kant RH, Mir N, Sarwar S, Gupta S, Najeeb R. Role of maternal serum lactate dehydrogenase as a biochemical marker in preeclampsia. IOSR Journal of Dental And Medical Sciences. 2005; 14(7): 12-19.

18. Qublan HS et al. Lactic dehydrogenase as a biochemical marker of adverse pregnancy outcome in severe pre-eclampsia.Med Sci Monit,2005;11(8):393-97

19. Singh P, Gaikwad HS, Marwah S, Mittal P, Kaur C. Role Of Serum Lactate Dehydrogenase In Pregnancy Induced Hypertension With Its Adverse Feto-Maternal Outcome- A Case-Control Study. Journal Of Clinical And Diagnostic Research. 2018; 12(5): 19-23.

20. Catanzarite VA, Steinberg SM, Mosley CA, et al. Severe preeclampsia with fulminant and extreme elevation of aspartate aminotransferase and lactate dehydrogenase levels: high risk for maternal death. Am J Perinatol. 1995 Sep;12(5):310-3.

21. Ciryam SS, Gomathy E. Study of serum lactate dehydrogenase level and seasonal variation in preeclampsia and eclampsia with its obstetric outcome. Int J Reprod Contracept Obstet Gynecol. 2017; 6(8): 3533-36.

22. Malarewics A, Gruszka O, Szymkiewicz J, Rogale J. The usefulness of routine laboratory tests in the evaluation of sudden threat of pregnant women and fetus in preeclampsia. Ginecol Pol. 2006; 77(4): 276-84.

\section{How to cite this article?}

K. Omkara Murthy, B. S. Dhananjaya, S. Shazi. To study the correlation of serum lactate dehydrogenase (LDH) levels in women with preeclampsia on maternal and perinatal outcome.Obs Rev:J obstet Gynecol 2019;5(1):19-25.doi:10. 17511/joog.2019.i01.04. 